\title{
基于芳基烯胺酯的环化反应合成苯并菲啶类似物及其细胞毒活性研究
}

\author{
王增博 ${ }^{\dagger}$ 田成 ${ }^{\dagger}$ 刘晴晴张玮潘成学* 苏桂发* \\ (广西师范大学化学与药学学院 药用资源化学与药物分子工程国家重点实验室 桂林 541004)
}

\begin{abstract}
摘要 苯并菲啶生物碱具有抗肿瘤、抗病毒、抗炎及抗菌等广泛生物活性, 因此其类似物的合成与活性研究引起了许 多有机合成及药物化学研究者的兴趣. 以 3-异色酮及芳胺等为原料，以烯胺酯的环化反应为关键步骤，经 3 4 步反应 合成了 23 个未见文献报道的苯并菲啶类似物, 目标化合物结构经 ${ }^{1} \mathrm{H} \mathrm{NMR},{ }^{13} \mathrm{C} \mathrm{NMR}$ 和 HRMS 表征和确认. 采用噻唑 蓝(MTT)法测试了目标化合物对人肿瘤细胞 MGC-803, HepG2, NCI-H460, SKOV3, T-24 和人正常细胞 HL-7702 的体外 细胞毒活性. 发现只有很少量化合物对受试肿瘤细胞显示中等强度的增殖抑制活性，其中 2,3-二甲氧基-6(1H)-异色并 [4,3-c]喹啉 $(\mathbf{4 j})$ 对人膀胱癌细胞 T-24 和 2 -氯异色酮并 $[4,3-c]$ 喹啉 $(\mathbf{5 f})$ 对人肺癌细胞 NCI-H460 的 $\mathrm{IC}_{50}$ 值分别为 15.8 和 16.7 $\mu \mathrm{mol} / \mathrm{L}$.
\end{abstract}

关键词 苯并菲啶生物碱; 环化反应; 天然产物类似物; 细胞毒活性

\section{Study on the Synthesis of Benzophenanthridine Analogues via the Cyclization Reaction of Aryl-enamine Ester and Their Cytotoxicity}

\author{
Wang, Zengbo ${ }^{\dagger}$ \\ Tian, Cheng ${ }^{\dagger}$ \\ Liu, Qingqing \\ Zhang, Wei \\ Pan, Chengxue* \\ $\mathrm{Su}$, Guifa*
}

(State Key Laboratory for Chemistry and Molecular Engineering of Medicinal Resources; School of Chemistry and Pharmaceutical Sciences, Guangxi Normal University, Guilin 541004)

\begin{abstract}
Study on the synthesis and bioactivity of benzophenanthridine alkaloids or its analogues had been the interests of many reserach groups who dedicated to organic synthsis or medicinal chemistry, due to their broad spectrum of biological activities such as antitumor, antiviral, antiinflammatory, antibacterial and so on. In this paper, twenty three novel analogue of benzophenanthridines were synthesized starting from isochroman-3-one and aromatic amines in $3 \sim 4$ steps via the cyclization reaction of aryl-enamine ester as the key transformation. The structures of the targeted compounds were characterized and comfirmed by ${ }^{1} \mathrm{H}$ NMR, ${ }^{13} \mathrm{C}$ NMR and HRMS. In vitro cytotoxic activity against a panel of human tumor cell lines (MGC-803, HepG2, NCI-H460, SKOV3, T-24) and nomal cell HL-7702 was also evaluated via methyl thiazolyl tetrazolium (MTT) assay. The result indicated that only a very few of the targeted compounds exhibted moderate cytotoxic activity against the tested cell lines. Among them 2,3-dimethoxy-isochrysen[4,3-c]quinoline (4j) and 2-chloro-isochromone[4,3-c]quinoline (5f) displayed moderate antiproliferative activity against human tumor cell lines on T-24 and NCI-H460 with $\mathrm{IC}_{50}$ values of 15.8 and 16.7 $\mu \mathrm{mol} / \mathrm{L}$, respectively.
\end{abstract}

Keywords benzophenanthridine; cyclization reaction; analogue of natural product; cytotoxicity

苯并菲啶类生物碱(benzo[c]phenanthridine alkaloids)是一类重要的异喹啉生物碱, 具有四环母核结构 (图 1, A). 这类生物碱大多数具有良好的抗肿瘤、抗病 毒、抗炎及抗菌等生物活性 ${ }^{[1]}$, 自 20 世纪 90 年代以来,
针对苯并菲啶类生物碱及其衍生物的分离、合成及活性 研究, 成为了有机化学及药物化学的一个研究热点 ${ }^{[2 \sim 7]}$, 其中两面针碱、血根碱(图 1, B, C)的抗肿瘤及二氢白屈 菜红碱(图 1, D) 的抗病毒活性更是受到了广泛关注 ${ }^{[8 \sim 15]}$.

\footnotetext{
* Corresponding authors. E-mail: chengxuepan@163.com; gfysglgx@163.com

Received November 4, 2018; revised January 18, 2019; published online April 2, 2019.

Project supported by the National Natural Science Foundation of China (No. 21462008), the Natural Science Foundation of Guangxi Province (Nos 2015GXNSFDA139009, 2017GXNSFDA198045), and the Ministry of Education of China (No. IRT 16R15).

国家自然科学基金(No. 21462008)、广西自然科学基金(Nos. 2015GXNSFDA139009, 2017GXNSFDA198045)和教育部创新团队基金(No. IRT 16R15) 资助项目.

†共同第一作者(These authors contributed equally to this work)
} 
虽然苯并菲啶类生物碱具有广泛生物活性, 但由于 大部分生物活性较低, 而活性强的化合物如两面针 碱 ${ }^{[12]}$ 及血根碱 ${ }^{[13 \sim 15]}$ 等又具有很强的毒性. 因此, 依据 生物电子等排体替换理论对其进行结构改造, 成为了许

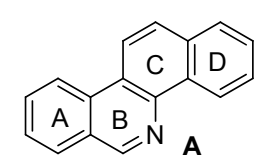

苯并菲啶母核结构<smiles>C[n+]1cc2ccccc2c2ccc3cc4c(cc3c21)OCO4</smiles>

血根碱<smiles>[R]c1cc2c[n+](C)c3c4cc5c(cc4ccc3c2cc1[R])OCO5</smiles>

两面针碱<smiles>[R]c1ccc2c(c1[R])CN(C)c1c-2ccc2cc3c(cc12)OCO3</smiles>

图 1 苯并菲啶生物碱的母核结构及其代表化合物

Figure 1 Core structures and representatives of benzophenanthridine

多药物化学工作者的研究课题. 最具有代表性的研究工 作主要包括 Lavoie ${ }^{[16 ~ 18]}$ 及 Cushman 课题组 ${ }^{[19]}$ 报道的苯 并菲啶类似物 $\mathbf{D} \sim \mathbf{G}$ (图 2), 研究发现 $\mathbf{D}$ (也称 ARC-111) 具有很强的拓扑异构酶 I 的毒化作用, 其抗肿瘤活性是 喜树碱的几十倍 ${ }^{[16]}$. E、 $\mathbf{F}^{[17,18]}$ 及 $\mathrm{ARC}-111$ 的衍生物 $\mathbf{G}^{[19]}$ 也都显示出很强的抗肿瘤活性, 部分化合物的 $\mathrm{IC}_{50}$ 值达纳摩尔级.

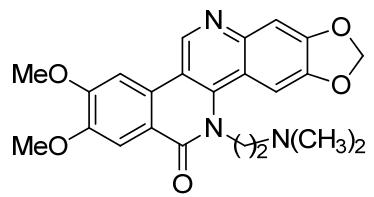<smiles>[R]c1cccc2cccc([R])c12</smiles>
D ARC-111<smiles></smiles><smiles>[R]c1cccc2c(=O)n([R])c3c4ccccc4nc([R])c3c12</smiles>

图 2 化合物 $\mathbf{D} \sim \mathbf{G}$ 的结构

Figure 2 Structures of compounds $\mathbf{D} \sim \mathbf{G}$

虽然以上两个课题组报道的苯并菲啶类似物具有 很好的生物活性，但他们发展的合成路线却不太理想, 不易于实现目标产物的结构多样化. 比如 Lavoie 课题组 的合成路线 ${ }^{[16,20 ~ 24]}$ 是以胡椒醛为起始原料, 需要经过至 少 9 步反应才能够得到目标产物. Cushman 课题组 ${ }^{[19]}$ 的 路线则是从不容易得到的高邻苯二甲酸䣶出发, 经至少 7 步反应合成得到(Scheme 1), 且两个课题组发展的合 成路线均不容易实现目标产物中取代基多样化. 最近, 该课题组还发展了一条以 2-溴芳甲酰胺及 4-溴喹啉为 原料经钯催化的 Catellani 反应来合成 ARC-111 衍生物
的新方法 ${ }^{[25]}$.

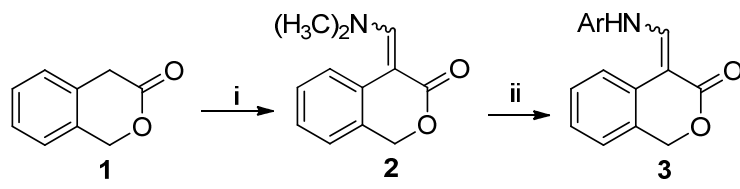

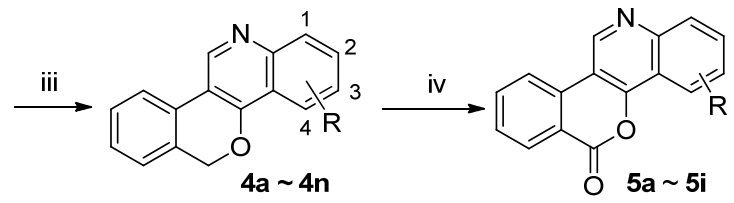

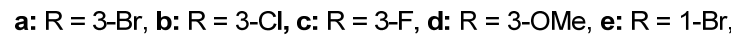
f: $\mathrm{R}=2-\mathrm{Cl}, \mathbf{g}: \mathrm{R}=1-\mathrm{F}, \mathbf{h}: \mathrm{R}=1-\mathrm{Cl}, \mathbf{i}: \mathrm{R}=\mathrm{H}$, j: $\mathrm{R}=2,3-(\mathrm{OMe})_{2}$, k: $\mathrm{R}=3-\mathrm{Me}, \mathrm{I}: \mathrm{R}=1-\mathrm{OMe}, \mathrm{m}: \mathrm{R}=1-\mathrm{Me}, \mathbf{n}: \mathrm{R}=4-\mathrm{Cl}$.

Reagents and conditions: (i) DMFDMA, 6 h; (ii) $\mathrm{ArNH}_{2}, \mathrm{AcOH}, 8 \mathrm{~h}$; (iii) $\mathrm{POCl}_{3}$, dioxane, $12 \mathrm{~h}$; (iv) Jones reagent, DCE, reflux, $12 \mathrm{~h}$.

\section{图式 1 苯并菲啶类似物的合成}

Scheme 1 Synthesis of the analogs of benzophenanthridine

为了获得结构及取代基多样化的苯并菲啶电子等 排体类似物, 我们发展了以 3-异色酮(1)及芳胺等为原 料, 以烯胺酯的环化反应为关键步骤, 经 $3 \sim 4$ 步反应合 成得到了 23 个未见文献报道的，具有类似苯并菲啶四 环结构的二氢苯并菲啶或苯并菲啶类似物 $4 a \sim 5 i$. 并对 这些化合物的细胞毒活性进行了测试.

\section{1 结果与讨论}

\section{1 目标化合物的合成}

在探索由 3 转化为 $\mathbf{4}$ 的过程中, 我们以中间体 $3 i$ 为 底物，尝试了许多不同的环化反应条件(表 1), 发现当 $3 \mathbf{i}$ 在 10 equiv. $\mathrm{POCl}_{3}$ 存在下于 $1,4-$ 二氧六环中回流时，可 以 $68 \%$ 的收率得到目标环化产物 $4 \mathbf{i}$. 产物 4 可看成是二 氢苯并菲啶类生物碱的电子等排体类似物. 以不同芳胺 为原料合成具有不同取代基的底物 $\mathbf{3}$, 当取代基为甲氧 基、甲基等供电子基团，或者氟、氯、澳等弱的吸电子

表 1 环化反应条件的探索

Table 1 Exploration the conditions of cyclization

\begin{tabular}{|c|c|c|c|}
\hline Entry & Solvent & Additive & Yield/\% \\
\hline 1 & $\mathrm{Ph}_{2} \mathrm{O}$ & No & $\mathrm{NR}^{a}$ \\
\hline 2 & $\mathrm{Ph}_{2} \mathrm{O}$ & TfOH (5 equiv.) & NR \\
\hline 3 & $\mathrm{Ph}_{2} \mathrm{O}$ & $\mathrm{BF}_{3} \cdot \mathrm{OEt}$ ( 5 equiv.) & NR \\
\hline 4 & $\mathrm{Ph}_{2} \mathrm{O}$ & PPA (5 equiv.) & 0 \\
\hline 5 & $\mathrm{BF}_{3}-\mathrm{OEt}$ & No & NR \\
\hline 6 & Xylene & TfOH (5 equiv.) & NR \\
\hline 7 & Xylene & $\mathrm{BF}_{3} \cdot \mathrm{OEt}(5$ equiv. $)$ & NR \\
\hline 8 & Xylene & $\mathrm{POCl}_{3}$ (5 equiv.) & 31 \\
\hline 9 & Xylene & $\mathrm{POCl}_{3}(10$ equiv. $)$ & 42 \\
\hline 10 & Xylene & $\mathrm{POCl}_{3}(15$ equiv. $)$ & 42 \\
\hline 11 & Dioxane & $\mathrm{POCl}_{3}(10$ equiv. $)$ & 68 \\
\hline 12 & Dioxane & $\mathrm{POCl}_{3}$ (15 equiv. $)$ & 66 \\
\hline
\end{tabular}

${ }^{a}$ No reaction. 
基团时，在该条件下均可以比较理想的收率得到环化产 物 4. 但如果取代基为硝基或酯基等强吸电子基团时, 在该条件下基本不能生发生相应的环化反应.

芳胺上取代基的位置对反应产率也有明显的影响, 当取代基位于氨基对位时, 环化反应产率要比取代基处 于邻位的底物要高. 当取代基处于氨基间位时，以间氯 苯胺所得到的底物 3f 的环化反应为例, 环化反应主要 是生成取代基在对位的产物 $\mathbf{4 f}$ (产率 $72 \%$ ), 取代基邻位 的环化产物 $4 \mathbf{n}$ 的产率仅为 $8 \%$, 这可能是受到以下两个 因素共同影响的结果: 一是邻位环化有相对比较大的位 阻效应，二是邻位受到氯原子的 $-\mathrm{I}$ 效应要比对位的强.

我们推测由 3 转化为 4 的反应历程如 Scheme 2 所 示. $\mathrm{POCl}_{3}$ 作用于内酯的羰基氧，同时导致双键移位形 成磷酸酯衍生物 M1, 接着 M1 在加热条件下发生 $6 \pi$ 或 $10 \pi$ 电环化反应形成中间体 M2, M2 进一步发生消除反 应生成化合物 4

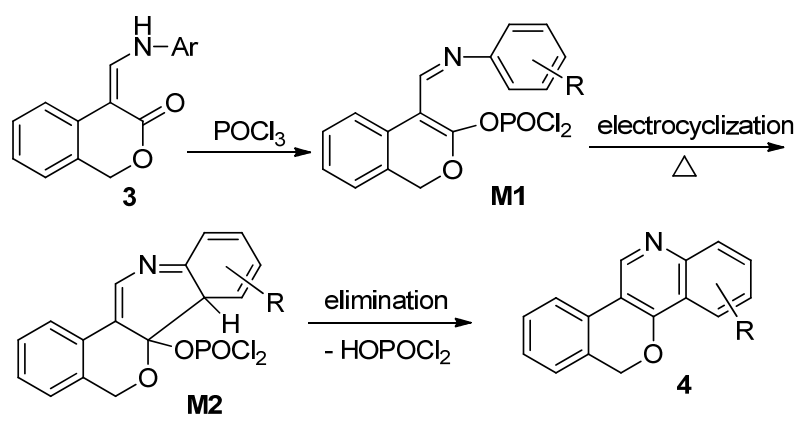

图式 2 化合物 $\mathbf{3}$ 转化为 $\mathbf{4}$ 的可能反应历程

Scheme 2 Proposed mechanism for the transformation of 3 to 4

为了获得苯并菲啶类似物 $\mathbf{5}$, 我们进一步探索了化 合物 4 氧化成 5 的转化. 尝试了许多不同的反应条件: 分别以二氯甲烷(DCM)、1,2-二氯乙烷(DCE)、四氢呋喃 (THF)和 1,4-二氧六环作溶剂, 以活性二氧化锰、三氧化 铬或 PCC 等为氧化剂, 但反应基本不能发生或产率很 低(12\% 21\%). 后面改用 jones 试剂为氧化剂, 在 DCE 中回流反应，可以以中等产率得到目标产物 $\mathbf{5}$.

在试图将 5 进一步转化成 ARC-111 的衍生物 $\mathbf{G}$ 时, 尝试了 $5 \mathbf{a}$ 与胺类化合物分别在 1,4 -二氧六环、甲苯、 二甲苯、 DMF 及 DMSO 回流反应, 但遗憾的是没有得 到预期的目标化合物 $\mathbf{G}$, 反应仅停留在 $\mathbf{5 a}$ 的胺解开环 产物 6. 根据化合物 $\mathbf{6}$ 的碳谱数据, 其化学位移最高的 $\mathbf{C}$ 的核磁共振信号均出现在 $\delta 175$ 附近, 可知胺解开环产 物 6 主要是以 M2 (4-差基喹啉)的形式存在. 其无法进 一步发生分子内芳环的亲核取代反应生成化合物 $\mathbf{G}$ ，很 可能是差基的离去能力及酰胺中 $\mathrm{N}$ 原子的亲核能力都 比较弱. 为此尝试了先对 4-差基喹啉中的羟基进行甲磺 酰化, 然后在碳酸钾、叔丁醇钾、钠氢等碱性条件下进
行反应，但均不能发生反应。说明进行甲磺酰化后，酚 着基的甲基磺酸酯的离去能力还不足以让环化反应顺 利进行.

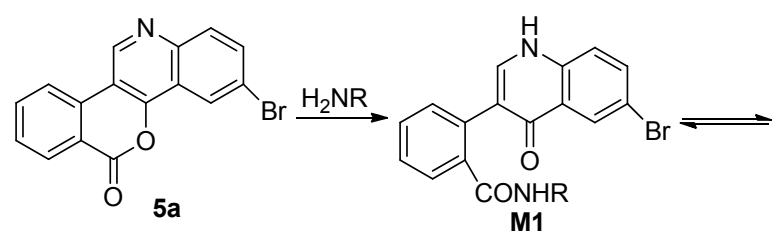<smiles>[Y][R16](=O)c1ccccc1-c1cnc2ccc(Br)cc2c1O</smiles>

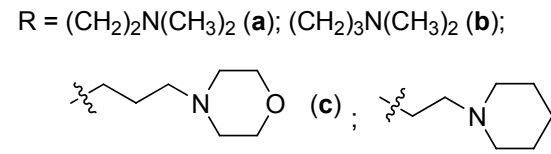
(d)

图式 3 以 $\mathbf{5}$ 为原料合成 $\mathbf{G}$ 的衍生物的尝试 Scheme 3 Investigation on the synthesis of $\mathbf{G}$ from $\mathbf{5}$

\section{2 化合物的细胞毒活性}

以喜树碱 (CPT)为对阳性对照, 用噻唑蓝(MTT)法 测试了化合物 $4 \sim 6$ 对五种人源肿瘤细胞株(胃癌细胞 MGC-803、肺癌细胞 NCI-H460、卵巢癌细胞 KOV3、 膀胱癌细胞 T-24、肝癌细胞 HepG2)和人正常肝细胞 7702 的体外细胞毒活性, 测试结果见表 2.

从表 2 可以看出，所合成的苯并菲啶类似物中，绝 大部分化合物几乎不显示明显的细胞毒活性, 特别是对 人的正常肝细胞 HL-7702. 化合物 $\mathbf{4 j}$ 和 $\mathbf{5 f}$ 对所受试肿 瘤细胞总体上显示出较强的体外生长抑制作用，其中 $\mathbf{4 j}$ 对人膀胱癌细胞 T-24 和 $\mathbf{5 f}$ 对人肺癌细胞 NCI-H460 的 $\mathrm{IC}_{50}$ 值分别为 15.8 和 $16.7 \mu \mathrm{mol} \cdot \mathrm{L}^{-1}$. 从表 2 还可看出, 将二氢苯并菲啶衍生物 $\mathbf{4}$ 中的亚甲基氧化成羰基，所得 到的化合物 5 对肿瘤细胞的生长抑制活性会有所提高. 另外，D 环上的取代基种类对化合物的细胞毒活性也有 明显的影响，当取代基为溴 $(4 a, 5 a, 5 e)$ 、氯(5f)及两个甲 氧基 $(4 \mathbf{j})$ 时，化合物显示较高的细胞毒活性.

此外, 由于化合物 6 很可能是 $\mathrm{ARC}-111$ 的衍生物 $\mathbf{G}^{[12]}$ 的体内代谢产物之一，化合物 $\mathbf{6}$ 没有明显细胞毒活 性, 说明 $\mathbf{G}$ 在体内不太容易代谢成 $\mathbf{6}$ 的胺解开环形式, 同时说明 ARC-111 及其衍生物 $\mathbf{G}$ 保持它们完整的四环 骨架, 对它们的抗肿瘤活性具有重要影响.

\section{2 结论}

本文发展了一条基于 $\mathrm{POCl}_{3}$ 促进的芳基烯胺酯的环 化反应为关键步骤来合成二氢苯并菲啶及苯并菲啶类 似物的新方法. 以 3 -异色酮及芳胺等为原料，经 3 4 步 
表 2 化合物 $\mathbf{4} \sim \mathbf{6}$ 对受试细胞的体外细胞毒活性 $\left[\mathrm{IC}_{50} /\left(\mu \mathrm{mol} \cdot \mathrm{L}^{-1}\right)\right]$

Table 2 In vitro cytotoxic activities of $\mathbf{4} \sim \mathbf{6}$ against the tested cell lines $\left[\mathrm{IC}_{50} /\left(\mu \mathrm{mol} \cdot \mathrm{L}^{-1}\right)\right]$

\begin{tabular}{|c|c|c|c|c|c|c|}
\hline Compd. & MGC-803 & NCI-H460 & SKOV3 & $\mathrm{T}-24$ & HepG2 & 7702 \\
\hline $4 a$ & $30.2 \pm 3.1$ & $38.7 \pm 4.0$ & $>100$ & $>100$ & $21.4 \pm 1.5$ & $>100$ \\
\hline $4 b$ & $>100$ & $>100$ & $70.2 \pm 0.4$ & $>100$ & $92.3 \pm 8.2$ & $>100$ \\
\hline $4 c$ & $>100$ & $>100$ & $>100$ & $>100$ & $>100$ & $>100$ \\
\hline 4d & $>100$ & $>100$ & $>100$ & $61.3 \pm 3.4$ & $65.7 \pm 3.9$ & $>100$ \\
\hline $4 e$ & $29.4 \pm 1.2$ & $>100$ & $>100$ & $>100$ & $>100$ & $>100$ \\
\hline $4 f$ & $>100$ & $>100$ & $>100$ & $>100$ & $>100$ & $>100$ \\
\hline $4 g$ & $>100$ & $>100$ & $>100$ & $>100$ & $57.9 \pm 2.6$ & $>100$ \\
\hline $4 h$ & $>100$ & $>100$ & $>100$ & $55.7 \pm 3.1$ & $>100$ & $>100$ \\
\hline $4 i$ & $>100$ & $>100$ & $>100$ & $>100$ & $>100$ & $>100$ \\
\hline $4 j$ & $22.3 \pm 1.2$ & $48.0 \pm 4.5$ & $73.9 \pm 6.6$ & $15.8 \pm 2.0$ & $84.6 \pm 6.2$ & $>100$ \\
\hline $4 k$ & $>100$ & $>100$ & $>100$ & $55.9 \pm 3.3$ & $>100$ & $>100$ \\
\hline 41 & $>100$ & $>100$ & $>100$ & $>100$ & $>100$ & $>100$ \\
\hline $4 m$ & $>100$ & $>100$ & $>100$ & $70.9 \pm 3.1$ & $>100$ & $>100$ \\
\hline $4 n$ & $>100$ & $>100$ & $>100$ & $>100$ & $>100$ & $>100$ \\
\hline $5 a$ & $23.0 \pm 1.5$ & $84.9 \pm 5.7$ & $>100$ & $66.2 \pm 3.0$ & $87.3 \pm 5.4$ & $>100$ \\
\hline $5 \mathbf{b}$ & $39.2 \pm 1.8$ & $>100$ & $82.6 \pm 5.1$ & $>100$ & $67.5 \pm 3.7$ & $>100$ \\
\hline $5 c$ & $66.2 \pm 4.0$ & $>100$ & $39.9 \pm 3.3$ & $>100$ & $>100$ & $>100$ \\
\hline $5 d$ & $37.0 \pm 1.4$ & $74.9 \pm 3.9$ & $>100$ & $>100$ & $64.9 \pm 4.0$ & $>100$ \\
\hline $5 e$ & $34.7 \pm 2.1$ & $86.0 \pm 5.2$ & $>100$ & $88.9 \pm 8.2$ & $42.1 \pm 2.7$ & $>100$ \\
\hline $5 f$ & $29.6 \pm 1.6$ & $16.7 \pm 1.2$ & $27.8 \pm 3.0$ & $38.0 \pm 2.3$ & $>100$ & $>100$ \\
\hline $5 \mathrm{~g}$ & $58.6 \pm 3.4$ & $>100$ & $>100$ & $>100$ & $67.0 \pm 4.3$ & $>100$ \\
\hline $5 \mathrm{~h}$ & $95.2 \pm 8.4$ & $49.6 \pm 3.0$ & $>100$ & $>100$ & $>100$ & $>100$ \\
\hline $5 \mathbf{i}$ & $>100$ & $>100$ & $>100$ & $>100$ & $>100$ & $>100$ \\
\hline $6 a$ & $>100$ & $>100$ & $>100$ & $>100$ & $>100$ & $>100$ \\
\hline $6 b$ & $>100$ & $>100$ & $>100$ & $>100$ & $>100$ & $>100$ \\
\hline $6 c$ & $>100$ & $>100$ & $>100$ & $>100$ & $>100$ & $>100$ \\
\hline 6d & $>100$ & $>100$ & $>100$ & $>100$ & $>100$ & $>100$ \\
\hline CPT & $7.8 \pm 1.1$ & $19.4 \pm 2.4$ & $18.8 \pm 2.0$ & $19.0 \pm 2.5$ & $12.7 \pm 0.9$ & $15.6 \pm 1.2$ \\
\hline
\end{tabular}

反应得到目标化合物. 共合成得到了 23 个未见文献报 道的苯并菲啶类似物 $4 a \sim 5 i$, 还初步研究了化合物 5 的 后续转化, 并用 MTT 法测试了目标化合物对人肿瘤细 胞 MGC-803, HepG2, NCI-H460, SKOV3, T-24 和人正常 细胞 HL-7702 的体外细胞毒活性. 结果发现, 绝大部分 化合物几乎不显示明显的细胞毒, 只有 $4 \mathbf{j}$ 和 $\mathbf{5 f}$ 对受试 肿瘤细胞显示了中等强度的细胞毒活性.

\section{3 实验部分}

\section{1 仪器与试剂}

超导核磁共振仪: Bruker AV $400 \mathrm{MHz}$, Bruker AV $500 \mathrm{MHz}$ (内标: TMS); 高分辨质谱仪: ESQUIRE HCT 型(美国布鲁克・道尔顿公司); 熔点仪: XT4A 熔点测定 仪(北京科仪电光仪器厂); M1000 多功能酶标仪(Tecan 公司); 硅胶: 青岛海洋化工集团公司. 所有试剂均为市 售的化学纯或分析纯试剂.

\section{2 实验方法}

\subsubsection{4- $N$-芳亚甲基(1H)-异色-3-酮(3)的合成}

将化合物 1 (1.48 g, $10.00 \mathrm{mmol})$ 和 DMFDMA $(N, N$ -
二甲基甲酰胺二甲基缩醛， $15 \mathrm{~mL}$ )加到 $100 \mathrm{~mL}$ 的单口 圆底烧瓶中, $\mathrm{N}_{2}$ 保护下 $100{ }^{\circ} \mathrm{C}$ 加热傥拌反应 $6 \mathrm{~h}$ (TLC 监 测反应进程). 反应完成后, 减压蒸去溶剂, 得到黄色油 状物 2. 粗产物直接用于下一步反应.

依次往 2 中加入芳胺 $\left(10.0 \mathrm{mmol}\right.$ )和 $15 \mathrm{~mL}$ 乙酸, $\mathrm{N}_{2}$ 保护, 电磁搅拌下加热回流反应 $8 \mathrm{~h}$ (TLC 监测反应进 程). 减压蒸去溶剂, 小心加入饱和 $\mathrm{NaHCO}_{3}$ 溶液, 调节 溶液的 $\mathrm{pH}$ 值至 7 左右, 混合液用乙酸乙酯萃取(30 $\mathrm{mL} \times 3)$, 合并萃取液, 饱和食盐水洗 $(30 \mathrm{~mL})$, 无水 $\mathrm{Na}_{2} \mathrm{SO}_{4}$ 干燥, 减压蒸去乙酸乙酯, 硅胶柱层析提纯[洗 脱剂: $V$ (石油醚) $： V($ 乙酸乙酯 $)=6: 1$ ] 得到产物 3 , 产率 $71 \% \sim 90 \%$. 直接用于下一步反应.

\subsubsection{6(1H)-异色并[4,3-c]喹啉(4)的合成}

将化合物 $3(1.0 \mathrm{mmol}) 、 1,4-$ 二氧六环 $(15 \mathrm{~mL})$ 和 $\mathrm{POCl}_{3}(1.0 \mathrm{~mL}, 10 \mathrm{mmol})$ 加入到圆底烧瓶中, $\mathrm{N}_{2}$ 保护, 回流反应 $12 \mathrm{~h}$ (TLC 监测反应进程). 减压蒸去大部分过 量的 $\mathrm{POCl}_{3}$. 冷却后加入少量冰水, 用饱和 $\mathrm{NaHCO}_{3}$ 溶 液调混合液的 $\mathrm{pH}$ 值约 7 , 乙酸乙酯萃取 $(30 \mathrm{~mL} \times 3)$, 饱 和食盐水洗 $(30 \mathrm{~mL})$, 无水 $\mathrm{Na}_{2} \mathrm{SO}_{4}$ 干燥, 减压蒸除溶剂, 
硅胶柱层析提纯(洗脱剂: $V_{\text {石油醇 }}: V_{\text {乙配醂 }}=8: 1$ )得到产 物 4 .

3-溴-6(1H)-异色并[4,3-c]喹啉(4a): 黄色油状液体, 产率 64\%. ${ }^{1} \mathrm{H}$ NMR $\left(400 \mathrm{MHz}, \mathrm{CDCl}_{3}\right) \delta: 8.82(\mathrm{~s}, 1 \mathrm{H})$, $8.49(\mathrm{~d}, J=2.1 \mathrm{~Hz}, 1 \mathrm{H}), 8.06(\mathrm{~d}, J=9.0 \mathrm{~Hz}, 1 \mathrm{H}), 7.89(\mathrm{dd}$, $J=9.0,2.1 \mathrm{~Hz}, 1 \mathrm{H}), 7.63 \sim 7.60(\mathrm{~m}, 1 \mathrm{H}), 7.55 \sim 7.45(\mathrm{~m}$, $2 \mathrm{H}), 7.30 \sim 7.27(\mathrm{~m}, 1 \mathrm{H}), 4.47(\mathrm{~d}, J=11.7 \mathrm{~Hz}, 1 \mathrm{H}), 4.33$ $(\mathrm{d}, J=11.7 \mathrm{~Hz}, 1 \mathrm{H}) ;{ }^{13} \mathrm{C}$ NMR $\left(100 \mathrm{MHz}, \mathrm{CDCl}_{3}\right) \delta$ : $151.4,146.8,139.9,136.1,135.6,134.0,132.6,131.5$, $130.5,130.3,129.5,128.9,127.3,126.9,122.6,43.8$; HRMS (ESI) calcd for $\mathrm{C}_{16} \mathrm{H}_{11} \mathrm{BrNO}[\mathrm{M}+\mathrm{H}]^{+} 312.0024$, found 312.0005 .

3-氯-6(1H)-异色并[4,3-c]喹啉(4b): 黄色固体, 产 率 76\%. m.p. $100 \sim 101{ }^{\circ} \mathrm{C} ;{ }^{1} \mathrm{H}$ NMR $\left(400 \mathrm{MHz}, \mathrm{CDCl}_{3}\right)$ $\delta: 8.81(\mathrm{~s}, 1 \mathrm{H}), 8.31(\mathrm{~d}, J=2.3 \mathrm{~Hz}, 1 \mathrm{H}), 8.14(\mathrm{~d}, J=9.0$ $\mathrm{Hz}, 1 \mathrm{H}), 7.56(\mathrm{dd}, J=9.0,2.3 \mathrm{~Hz}, 1 \mathrm{H}), 7.63 \sim 7.60(\mathrm{~m}$, $1 \mathrm{H}), 7.55 \sim 7.45(\mathrm{~m}, 2 \mathrm{H}), 7.30 \sim 7.27(\mathrm{~m}, 1 \mathrm{H}), 4.47$ (d, $J=$ $11.7 \mathrm{~Hz}, 1 \mathrm{H}), 4.33(\mathrm{~d}, J=11.7 \mathrm{~Hz}, 1 \mathrm{H}) ;{ }^{13} \mathrm{C}$ NMR $(100$ $\left.\mathrm{MHz}, \mathrm{CDCl}_{3}\right) \delta: 151.3,146.7,140.0,136.1,135.7,134.4$, $132.6,131.5,131.4,130.5,130.3,129.5,128.9,126.9$, 123.6, 43.8; HRMS (ESI) calcd for $\mathrm{C}_{16} \mathrm{H}_{11} \mathrm{ClNO}[\mathrm{M}+\mathrm{H}]^{+}$ 268.0529, found 268.0514 .

3-氟-6(1H)-异色并[4,3-c]喹啉(4c): 黄色油状液体, 产率 79\%. ${ }^{1} \mathrm{H}$ NMR $\left(400 \mathrm{MHz}, \mathrm{CDCl}_{3}\right) \delta: 8.79(\mathrm{~s}, 1 \mathrm{H})$, $8.22(\mathrm{dd}, J=5.3,3.9 \mathrm{~Hz}, 1 \mathrm{H}), 7.94(\mathrm{dd}, J=9.6,2.8 \mathrm{~Hz}$, $1 \mathrm{H}), 7.64 \sim 7.57(\mathrm{~m}, 2 \mathrm{H}), 7.55 \sim 7.46(\mathrm{~m}, 2 \mathrm{H}), 7.30 \sim 7.27$ (m, 1H), $4.47(\mathrm{~d}, J=11.8 \mathrm{~Hz}, 1 \mathrm{H}), 4.34(\mathrm{~d}, J=11.7 \mathrm{~Hz}$, $1 \mathrm{H}) ;{ }^{13} \mathrm{C}$ NMR (100 MHz, $\left.\mathrm{CDCl}_{3}\right) \delta: 161.6$ (d, $J=253.8$ $\mathrm{Hz}, \mathrm{C}-\mathrm{F}), 150.4,145.3,140.3,136.0,135.8,132.6,132.5$, $130.5,130.3,129.5,128.8,127.3,127.2,120.9,120.6$, 108.6, 108.3, 43.8; HRMS (ESI) calcd for $\mathrm{C}_{16} \mathrm{H}_{11} \mathrm{FNO}$ $[\mathrm{M}+\mathrm{H}]^{+}$252.0824, found 252.0809 .

3-甲氧基-6(1H)-异色并[4,3-c]喹啉(4d): 黄色油状 液体, 产率 $64 \% .{ }^{1} \mathrm{H}$ NMR $\left(400 \mathrm{MHz}, \mathrm{CDCl}_{3}\right) \delta: 8.67(\mathrm{~s}$, 1H), 8.09 (d, $J=9.2 \mathrm{~Hz}, 1 \mathrm{H}), 7.62(\mathrm{~d}, J=7.4 \mathrm{~Hz}, 1 \mathrm{H})$, $7.55 \sim 7.44$ (m, $4 \mathrm{H}), 7.31 \sim 7.28(\mathrm{~m}, 1 \mathrm{H}), 4.48(\mathrm{~d}, J=11.7$ $\mathrm{Hz}, 1 \mathrm{H}), 4.35(\mathrm{~d}, J=11.7 \mathrm{~Hz}, 1 \mathrm{H}), 4.00(\mathrm{~s}, 3 \mathrm{H}) ;{ }^{13} \mathrm{C} \mathrm{NMR}$ $\left(100 \mathrm{MHz}, \mathrm{CDCl}_{3}\right) \delta: 159.2,148.3,144.3,139.4,136.3$, $136.1,131.9,131.3,130.6,130.1,129.3,128.7,127.2$, 123.3, 102.1, 55.7, 43.9; HRMS (ESI) calcd for $\mathrm{C}_{17} \mathrm{H}_{14} \mathrm{NO}_{2}$ $[\mathrm{M}+\mathrm{H}]^{+}$264.1024, found 264.1013.

1-澳-6(1H)-异色并[4,3-c]喹啉(4e): 黄色油状液体, 产率 63\%. ${ }^{1} \mathrm{H}$ NMR $\left(500 \mathrm{MHz}, \mathrm{CDCl}_{3}\right) \delta: 8.94(\mathrm{~s}, 1 \mathrm{H})$, $8.33(\mathrm{dd}, J=8.4,1.2 \mathrm{~Hz}, 1 \mathrm{H}), 8.16(\mathrm{dd}, J=7.5,1.2 \mathrm{~Hz}$, $1 \mathrm{H}), 7.63 \sim 7.61(\mathrm{~m}, 1 \mathrm{H}), 7.59 \sim 7.47(\mathrm{~m}, 3 \mathrm{H}), 7.29 \sim 7.26$ (m, 1H), 4.47 (d, $J=11.8 \mathrm{~Hz}, 1 \mathrm{H}), 4.34(\mathrm{~d}, J=11.8 \mathrm{~Hz}$, $1 \mathrm{H}) ;{ }^{13} \mathrm{C}$ NMR $\left(125 \mathrm{MHz}, \mathrm{CDCl}_{3}\right) \delta 151.7,145.3,141.6$, 136.1, 135.6, 134.2, 132.67, 130.5, 130.3, 129.6, 128.9, 128.4, 127.5, 125.2, 124.6, 43.8; HRMS (ESI) calcd for $\mathrm{C}_{16} \mathrm{H}_{11} \mathrm{BrNO}[\mathrm{M}+\mathrm{H}]^{+}$312.0024, found 312.0005 .

2-氯-6(1H)-异色并 [4,3-c]喹啉 (4f): 黄色油状液体, 产率 72\%. ${ }^{1} \mathrm{H}$ NMR $\left(500 \mathrm{MHz}, \mathrm{CDCl}_{3}\right) \delta: 8.78(\mathrm{~s}, 1 \mathrm{H})$, $8.14(\mathrm{dd}, J=8.4,1.3 \mathrm{~Hz}, 1 \mathrm{H}), 7.75(\mathrm{dd}, J=7.6,1.3 \mathrm{~Hz}$, $1 \mathrm{H}), 7.66(\mathrm{dd}, J=8.4,7.6 \mathrm{~Hz}, 1 \mathrm{H}), 7.62 \sim 7.59(\mathrm{~m}, 1 \mathrm{H})$, $7.53 \sim 7.47(\mathrm{~m}, 2 \mathrm{H}), 7.27 \sim 7.24(\mathrm{~m}, 1 \mathrm{H}), 4.47$ (d, $J=11.7$ $\mathrm{Hz}, 1 \mathrm{H}), 4.34(\mathrm{~d}, J=11.7 \mathrm{~Hz}, 1 \mathrm{H}) ;{ }^{13} \mathrm{C}$ NMR $(100 \mathrm{MHz}$, $\mathrm{CDCl}_{3}$ ) $\delta: 152.3,148.6,141.0,136.6,136.1,135.7,132.0$, $130.6,130.3,129.5,129.1,128.8,128.8,126.0,124.6$, 43.9; HRMS (ESI) calcd for $\mathrm{C}_{16} \mathrm{H}_{11} \mathrm{ClNO}[\mathrm{M}+\mathrm{H}]^{+}$ 268.0529, found 268.0513.

1-氟-6(1H)-异色并 [4,3-c]喹啉 $(\mathbf{4 g})$ : 黄色油状液体, 产率 61\%. ${ }^{1} \mathrm{H}$ NMR $\left(400 \mathrm{MHz}, \mathrm{CDCl}_{3}\right) \delta: 8.87(\mathrm{~s}, 1 \mathrm{H})$, $8.11(\mathrm{~d}, J=8.5 \mathrm{~Hz}, 1 \mathrm{H}), 7.68 \sim 7.61(\mathrm{~m}, 2 \mathrm{H}), 7.55 \sim 7.46$ (m, 3H), $7.31 \sim 7.28(\mathrm{~m}, 1 \mathrm{H}), 4.47(\mathrm{~d}, J=11.8 \mathrm{~Hz}, 1 \mathrm{H})$, $4.34(\mathrm{~d}, J=11.8 \mathrm{~Hz}, 1 \mathrm{H}) ;{ }^{13} \mathrm{C}$ NMR $\left(100 \mathrm{MHz}, \mathrm{CDCl}_{3}\right) \delta$ : $158.2(\mathrm{~d}, J=256.4 \mathrm{~Hz}, \mathrm{C}-\mathrm{F}), 151.3,141.0,138.7,136.1$, $135.7,132.9,130.4,129.6,128.9,127.9,127.8,120.3$, 114.5, 43.8; HRMS (ESI) calcd for $\mathrm{C}_{16} \mathrm{H}_{11} \mathrm{FNO}[\mathrm{M}+\mathrm{H}]^{+}$ 252.0824 , found 252.0810 .

1-氯-6(1H)-异色并 [4,3-c]喹啉(4h): 黄色油状液体, 产率 75\%. ${ }^{1} \mathrm{H}$ NMR $\left(500 \mathrm{MHz}, \mathrm{CDCl}_{3}\right) \delta: 8.95(\mathrm{~s}, 1 \mathrm{H})$, $8.28(\mathrm{~d}, J=8.5 \mathrm{~Hz}, 1 \mathrm{H}), 7.96(\mathrm{~d}, J=7.6 \mathrm{~Hz}, 1 \mathrm{H}), 7.66 \sim$ $7.62(\mathrm{~m}, 2 \mathrm{H}), 7.55 \sim 7.47(\mathrm{~m}, 2 \mathrm{H}), 7.30 \sim 7.27(\mathrm{~m}, 1 \mathrm{H})$, $4.47(\mathrm{~d}, J=11.8 \mathrm{~Hz}, 1 \mathrm{H}), 4.34(\mathrm{~d}, J=11.8 \mathrm{~Hz}, 1 \mathrm{H}) ;{ }^{13} \mathrm{C}$ NMR $\left(125 \mathrm{MHz}, \mathrm{CDCl}_{3}\right) \delta: 151.6,144.6,141.6,136.1$, $135.7,134.1,132.7,130.6,130.5,130.3,129.6,128.9$, 127.9, 127.5, 123.8, 43.8; HRMS (ESI) calcd for $\mathrm{C}_{16} \mathrm{H}_{11} \mathrm{ClNO}[\mathrm{M}+\mathrm{H}]^{+}$268.0529, found 268.0514.

6(1H)-异色并[4,3-c]喹啉(4i): 黄色油状液体, 产率 $68 \% .{ }^{1} \mathrm{H}$ NMR $\left(400 \mathrm{MHz}, \mathrm{CDCl}_{3}\right) \delta: 8.84(\mathrm{~s}, 1 \mathrm{H}), 8.32(\mathrm{~d}$, $J=8.4 \mathrm{~Hz}, 1 \mathrm{H}), 8.22(\mathrm{~d}, J=8.4 \mathrm{~Hz}, 1 \mathrm{H}), 7.85 \sim 7.79(\mathrm{~m}$, $1 \mathrm{H}), 7.73 \sim 7.68(\mathrm{~m} \mathrm{1H}), 7.63 \sim 7.59(\mathrm{~m}, 1 \mathrm{H}), 7.53 \sim 7.44$ (m, 2H), $7.30 \sim 7.27(\mathrm{~m}, 1 \mathrm{H}), 4.47(\mathrm{~d}, J=11.7 \mathrm{~Hz}, 1 \mathrm{H})$, $4.35(\mathrm{~d}, J=11.7 \mathrm{~Hz}, 1 \mathrm{H}) ;{ }^{13} \mathrm{C}$ NMR $\left(100 \mathrm{MHz}, \mathrm{CDCl}_{3}\right) \delta$ : $150.9,148.0,141.1,136.1,135.9,131.7,130.5,130.4$, $130.1,129.6,129.3,128.7,128.1,126.0,124.4,43.8$; HRMS (ESI) calcd for $\mathrm{C}_{16} \mathrm{H}_{12} \mathrm{NO}[\mathrm{M}+\mathrm{H}]^{+} 234.0919$, found 234.0904.

2,3-二甲氧基-6(1H)-异色并[4,3-c]喹啉(4j)：黄色油 状液体, 产率 64\%. ${ }^{1} \mathrm{H}$ NMR $\left(400 \mathrm{MHz}, \mathrm{CDCl}_{3}\right) \delta: 8.61$ 
(s, $1 \mathrm{H}), 7.62 \sim 7.59(\mathrm{~m}, 1 \mathrm{H}), 7.52 \sim 7.43(\mathrm{~m}, 4 \mathrm{H}), 7.30 \sim$ $7.27(\mathrm{~m}, 1 \mathrm{H}), 4.48(\mathrm{~d}, J=11.7 \mathrm{~Hz}, 1 \mathrm{H}), 4.35$ (d, $J=11.7$ $\mathrm{Hz}, 1 \mathrm{H}), 4.07$ (s, 6H); ${ }^{13} \mathrm{C}$ NMR $\left(100 \mathrm{MHz}, \mathrm{CDCl}_{3}\right) \delta$ : $153.1,151.1,148.6,145.3,139.0,136.4,136.2130 .8$, 130.1, 129.9, 129.1, 128.6, 121.6, 108.2, 102.1, 56.3, 56.2, 43.9; HRMS (ESI) calcd for $\mathrm{C}_{18} \mathrm{H}_{16} \mathrm{NO}_{3}[\mathrm{M}+\mathrm{H}]^{+}$ 294.1130, found 294.1115.

3-甲基-6(1H)-异色并[4,3-c]喹啉(4k)：黄色油状液 体, 产率 79\%. ${ }^{1} \mathrm{H}$ NMR $\left(400 \mathrm{MHz}, \mathrm{CDCl}_{3}\right) \delta: 8.75$ (s, $1 \mathrm{H}), 8.11 \sim 8.08(\mathrm{~m}, 2 \mathrm{H}), 7.67 \sim 7.60(\mathrm{~m}, 2 \mathrm{H}), 7.53 \sim 7.44$ (m, 2H), 7.29 (d, $J=7.2 \mathrm{~Hz}, 1 \mathrm{H}), 4.47(\mathrm{~d}, J=11.7 \mathrm{~Hz}$, 1H), $4.35(\mathrm{~d}, J=11.7 \mathrm{~Hz}, 1 \mathrm{H}), 2.62(\mathrm{~s}, 3 \mathrm{H}) ;{ }^{13} \mathrm{C}$ NMR $(100$ $\left.\mathrm{MHz}, \mathrm{CDCl}_{3}\right) \delta: 150.1,146.8,140.3,138.4,136.2,136.1$, $132.7,131.6,130.6,130.1,129.5,129.3,128.7,126.0$, 123.3, 43.9, 21.9; HRMS (ESI) calcd for $\mathrm{C}_{17} \mathrm{H}_{14} \mathrm{NO}[\mathrm{M}+$ $\mathrm{H}]^{+} 248.1075$, found 248.1060 .

1-甲氧基-6(1H)-异色并[4,3-c]喹啉(4I): 黄色油状液 体, 产率 60\%. ${ }^{1} \mathrm{H}$ NMR $\left(500 \mathrm{MHz}, \mathrm{CDCl}_{3}\right) \delta: 8.84(\mathrm{~s}$, $1 \mathrm{H}), 7.88(\mathrm{~d}, J=8.5 \mathrm{~Hz}, 1 \mathrm{H}), 7.64(\mathrm{~d}, J=8.1 \mathrm{~Hz}, 1 \mathrm{H})$, $7.62 \sim 7.59(\mathrm{~m}, 1 \mathrm{H}), 7.51 \sim 7.44(\mathrm{~m}, 2 \mathrm{H}), 7.30 \sim 7.27(\mathrm{~m}$, $1 \mathrm{H}), 7.19 \sim 7.16(\mathrm{~m}, 1 \mathrm{H}), 4.45(\mathrm{~d}, J=11.8 \mathrm{~Hz}, 1 \mathrm{H}), 4.33$ $(\mathrm{d}, J=11.8 \mathrm{~Hz}, 1 \mathrm{H}), 4.14$ (s, 3H); ${ }^{13} \mathrm{C}$ NMR $(125 \mathrm{MHz}$, $\mathrm{CDCl}_{3}$ ) $\delta: 155.5,149.5,141.4,139.8,136.1,135.9,132.4$, $130.6,130.2,129.4,128.7,128.5,127.3,116.1,108.7$, 56.3, 43.8; HRMS (ESI) calcd for $\mathrm{C}_{17} \mathrm{H}_{14} \mathrm{NO}_{2}[\mathrm{M}+\mathrm{H}]^{+}$ 364.1024, found 264.1009.

1-甲基-6(1H)-异色并[4,3-c]喹啉(4m): 黄色油状液 体, 产率 44\%. ${ }^{1} \mathrm{H}$ NMR $\left(400 \mathrm{MHz}, \mathrm{CDCl}_{3}\right) \delta: 8.85(\mathrm{~s}$, $1 \mathrm{H}), 8.19(\mathrm{~d}, J=8.4 \mathrm{~Hz}, 1 \mathrm{H}), 7.68(\mathrm{~d}, J=6.7 \mathrm{~Hz}, 1 \mathrm{H})$, $7.64 \sim 7.58(\mathrm{~m}, 2 \mathrm{H}), 7.54 \sim 7.45(\mathrm{~m}, 2 \mathrm{H}), 7.31 \sim 7.28(\mathrm{~m}$, $1 \mathrm{H}), 4.49(\mathrm{~d}, J=11.7 \mathrm{~Hz}, 1 \mathrm{H}), 4.36(\mathrm{~d}, J=11.7 \mathrm{~Hz}, 1 \mathrm{H})$, 2.88 (s, 3H); ${ }^{13} \mathrm{C}$ NMR $\left(100 \mathrm{MHz}, \mathrm{CDCl}_{3}\right) \delta: 149.8,147.4$, $141.3,137.8,136.3,136.2,131.4,130.7,130.6,130.2$, 129.3, 128.7, 127.9, 126.1, 122.5, 43.9, 26.9; HRMS (ESI) calcd for $\mathrm{C}_{17} \mathrm{H}_{14} \mathrm{NO}[\mathrm{M}+\mathrm{H}]^{+} 248.1075$, found 248.1061.

4-氯-6(1H)-异色并 [4,3-c]喹啉(4n): 黄色油状液体, 产率 $8 \%$ (合成 $4 \mathbf{f}$ 时的邻位环化产物). ${ }^{1} \mathrm{H}$ NMR (500 $\left.\mathrm{MHz}, \mathrm{CDCl}_{3}\right) \delta: 8.94(\mathrm{~s}, 1 \mathrm{H}), 8.31(\mathrm{~d}, J=1.7 \mathrm{~Hz}, 1 \mathrm{H})$, $8.16 \sim 8.15(\mathrm{~m}, 1 \mathrm{H}), 7.61(\mathrm{~d}, J=1.7 \mathrm{~Hz}, 1 \mathrm{H}), 7.57 \sim 7.47$ (m, $3 \mathrm{H}), 7.27 \sim 7.25(\mathrm{~m}, 1 \mathrm{H}), 4.45(\mathrm{~d}, J=11.8 \mathrm{~Hz}, 1 \mathrm{H})$, $4.33(\mathrm{~d}, J=11.8 \mathrm{~Hz}, 1 \mathrm{H}) ;{ }^{13} \mathrm{C}$ NMR $\left(100 \mathrm{MHz}, \mathrm{CDCl}_{3}\right) \delta$ : $151.3,150.4,139.8,136.5,136.0,134.6,131.7,130.3$, $130.3,130.2,130.2,129.6,129.4,128.9,123.6,43.9$; HRMS (ESI) calcd for $\mathrm{C}_{16} \mathrm{H}_{11} \mathrm{ClNO}[\mathrm{M}+\mathrm{H}]^{+} 268.0529$, found 268.0514 .

\subsection{3 异色酮并 $[4,3-c]$ 喹啉(5)的合成}

将化合物 $4(0.5 \mathrm{mmol})$ 溶于 DCE $(15 \mathrm{~mL})$, 再加入 jones 试剂(6 mL, $16.00 \mathrm{mmol}), \mathrm{N}_{2}$ 保护下加热回流反应 $12 \mathrm{~h}$ (TLC 监测反应进程). 冷却后加入饱和 $\mathrm{NaHCO}_{3}$ 调 节 $\mathrm{pH}$ 值至 7 左右, 乙酸乙酯萃取 $(30 \mathrm{~mL} \times 3)$, 饱和食盐 水洗 $(30 \mathrm{~mL})$, 无水 $\mathrm{Na}_{2} \mathrm{SO}_{4}$ 干燥, 减压蒸去溶剂, 硅胶 柱层析提纯 [洗脱剂: $V$ (石油醚) $: V$ (乙酸乙酯 $)=1: 4$ ] 得 到化合物 5.

3-溴异色酮并 [4,3-c]喹啉 (5a): 白色固体, 产率 $61 \%$. m.p. $>250{ }^{\circ} \mathrm{C} ;{ }^{1} \mathrm{H}$ NMR $\left(400 \mathrm{MHz}, \mathrm{CDCl}_{3}\right) \delta: 9.57$ $(\mathrm{s}, 1 \mathrm{H}), 8.67(\mathrm{~d}, J=2.1 \mathrm{~Hz}, 1 \mathrm{H}), 8.50 \sim 8.47(\mathrm{~m}, 1 \mathrm{H}), 8.33$ (d, $J=8.1 \mathrm{~Hz}, 1 \mathrm{H}), 8.02(\mathrm{~d}, J=8.9 \mathrm{~Hz}, 1 \mathrm{H}), 7.98 \sim 7.93$ (m, $1 \mathrm{H}), 7.88(\mathrm{dd}, J=8.9,2.1 \mathrm{~Hz}, 1 \mathrm{H}), 7.73 \sim 7.68(\mathrm{~m}$, $1 \mathrm{H}) ;{ }^{13} \mathrm{C} \mathrm{NMR}\left(100 \mathrm{MHz}, \mathrm{CDCl}_{3}\right) \delta: 159.6,152.1,147.2$, $145.7,135.7,134.5,133.0,131.1,130.9,129.9,124.4$, 122.0, 121.6, 121.2, 119.7, 109.8; HRMS (ESI) calcd for $\mathrm{C}_{16} \mathrm{H}_{9} \mathrm{BrNO}_{2}[\mathrm{M}+\mathrm{H}]^{+}$325.9816, found 325.9796 .

3-氯异色酮并 [4,3-c]喹啉 (5b): 白色固体, 产率 56\%. m.p. $>250{ }^{\circ} \mathrm{C} ;{ }^{1} \mathrm{H}$ NMR $\left(500 \mathrm{MHz}, \mathrm{CDCl}_{3}\right) \delta: 9.62$ (s, $1 \mathrm{H}), 8.54(\mathrm{~d}, J=2.3 \mathrm{~Hz}, 1 \mathrm{H}), 8.53 \sim 8.50(\mathrm{~m}, 1 \mathrm{H}), 8.34$ (d, $J=8.1 \mathrm{~Hz}, 1 \mathrm{H}), 8.26(\mathrm{~d}, J=8.9 \mathrm{~Hz}, 1 \mathrm{H}), 8.01 \sim 7.98$ $(\mathrm{m}, 1 \mathrm{H}), 7.82(\mathrm{dd}, J=8.9,2.3 \mathrm{~Hz}, 1 \mathrm{H}), 7.77 \sim 7.73(\mathrm{~m}$, 1H); HRMS (ESI) calcd for $\mathrm{C}_{16} \mathrm{H}_{9} \mathrm{ClNO}_{2}[\mathrm{M}+\mathrm{H}]^{+}$ 282.0322, found 282.0305 .

3-氟异色酮并 [4,3-c] 喹啉 (5c): 白色固体, 产率 51\%. m.p. $>250{ }^{\circ} \mathrm{C} ;{ }^{1} \mathrm{H}$ NMR (400 MHz, $\left.\mathrm{CDCl}_{3}\right) \delta: 9.52$ (s, 1H), $8.48(\mathrm{dd}, J=8.0,1.0 \mathrm{~Hz}, 1 \mathrm{H}), 8.33(\mathrm{~d}, J=8.1 \mathrm{~Hz}$, $1 \mathrm{H}), 8.16(\mathrm{dd}, J=9.2,5.1 \mathrm{~Hz}, 1 \mathrm{H}), 8.09(\mathrm{dd}, J=9.0,2.8$ $\mathrm{Hz}, 1 \mathrm{H}), 7.98 \sim 7.92(\mathrm{~m}, 1 \mathrm{H}), 7.72 \sim 7.67(\mathrm{~m}, 1 \mathrm{H}), 7.60 \sim$ $7.54(\mathrm{~m}, 1 \mathrm{H}) ;{ }^{13} \mathrm{C}$ NMR $\left(100 \mathrm{MHz}, \mathrm{CDCl}_{3}\right) \delta: 161.3(\mathrm{~d}$, $J=249.1 \mathrm{~Hz}, \mathrm{C}-\mathrm{F}), 159.6,152.7,145.7,144.6,135.7$, $133.1,131.9,131.1,129.8,121.6,121.2,121.2,119.5$, 109.6, 106.0; HRMS (ESI) calcd for $\mathrm{C}_{16} \mathrm{H}_{9} \mathrm{FNO}_{2}[\mathrm{M}+\mathrm{H}]^{+}$ 266.0617 , found 266.0602 .

3-甲氧基异色酮并 [4,3-c]喹啉(5d): 白色固体, 产率 56\%. m.p. $>250{ }^{\circ} \mathrm{C} ;{ }^{1} \mathrm{H}$ NMR (400 MHz, $\left.\mathrm{CDCl}_{3}\right) \delta: 9.43$ (s, $1 \mathrm{H}), 8.50 \sim 8.47(\mathrm{~m}, 1 \mathrm{H}), 8.33(\mathrm{~d}, J=8.0 \mathrm{~Hz}, 1 \mathrm{H}), 8.04$ (d, $J=9.2 \mathrm{~Hz}, 1 \mathrm{H}), 7.96 \sim 7.91(\mathrm{~m}, 1 \mathrm{H}), 7.71(\mathrm{~d}, J=2.8$ $\mathrm{Hz}, 1 \mathrm{H}), 7.70 \sim 7.65(\mathrm{~m}, 1 \mathrm{H}), 7.44(\mathrm{dd}, J=9.2,2.8 \mathrm{~Hz}$, $1 \mathrm{H}), 4.03(\mathrm{~s}, 3 \mathrm{H}) ;{ }^{13} \mathrm{C}$ NMR $\left(100 \mathrm{MHz}, \mathrm{CDCl}_{3}\right) \delta: 159.3$, $157.9,151.2,143.8,141.6,134.6,132.6,130.0,129.8$, 128.4, 122.9, 120.6, 120.1, 118.5, 108.4, 98.4, 55.0; HRMS (ESI) calcd for $\mathrm{C}_{17} \mathrm{H}_{12} \mathrm{NO}_{3}[\mathrm{M}+\mathrm{H}]^{+} 278.0817$, found 278.0802 .

1-溴异色酮并 $[4,3-c]$ 喹啉 $(\mathbf{5 e})$. 白色固体, 产率 
$51 \%$. m.p. $>250{ }^{\circ} \mathrm{C} ;{ }^{1} \mathrm{H}$ NMR $\left(500 \mathrm{MHz}, \mathrm{CDCl}_{3}\right) \delta: 9.71$ (s, $1 \mathrm{H}), 8.53 \sim 8.48(\mathrm{~m}, 2 \mathrm{H}), 8.35(\mathrm{~d}, J=8.0 \mathrm{~Hz}, 1 \mathrm{H})$, $8.17 \sim 8.14(\mathrm{~m}, 1 \mathrm{H}), 8.00 \sim 7.95(\mathrm{~m}, 1 \mathrm{H}), 7.74 \sim 7.70(\mathrm{~m}$, $1 \mathrm{H}), 7.58 \sim 7.53(\mathrm{~m}, 1 \mathrm{H}) ;{ }^{13} \mathrm{C} \mathrm{NMR}\left(125 \mathrm{MHz}, \mathrm{CDCl}_{3}\right) \delta$ : 159.7, 153.1, 146.2, 145.8, 135.8, 134.8, 133.0, 131.1, 130.0, 128.1, 124.8, 121.9, 121.6, 121.2, 120.0, 109.8; HRMS (ESI) calcd for $\mathrm{C}_{16} \mathrm{H}_{9} \mathrm{BrNO}_{2}[\mathrm{M}+\mathrm{H}]^{+} 325.9816$, found 325.9792 .

2-氯异色酮并 [4,3-c]哇啉(5f): 白色固体, 产率 49\%. m.p. $>250{ }^{\circ} \mathrm{C} ;{ }^{1} \mathrm{H}$ NMR $\left(400 \mathrm{MHz}, \mathrm{CDCl}_{3}\right) \delta: 9.54$ (s, $1 \mathrm{H}), 8.46(\mathrm{~d}, J=8.0 \mathrm{~Hz}, 1 \mathrm{H}), 8.42$ (d, $J=8.9 \mathrm{~Hz}, 1 \mathrm{H}), 8.30$ (d, $J=8.1 \mathrm{~Hz}, 1 \mathrm{H}), 8.12(\mathrm{~d}, J=1.8 \mathrm{~Hz}, 1 \mathrm{H}), 7.96 \sim 7.91$ (m, $1 \mathrm{H}), 7.71 \sim 7.66(\mathrm{~m}, 1 \mathrm{H}), 7.63(\mathrm{dd}, J=8.9,1.8 \mathrm{~Hz}$, $1 \mathrm{H}) ;{ }^{13} \mathrm{C}$ NMR $\left(100 \mathrm{MHz}, \mathrm{CDCl}_{3}\right) \delta: 159.6,153.0,149.2$, $146.6,137.2,135.7,133.2,131.1,129.7,128.7,128.5$, 123.4, 121.4, 121.1, 117.0, 109.4; HRMS (ESI) calcd for $\mathrm{C}_{16} \mathrm{H}_{9} \mathrm{ClNO}_{2}[\mathrm{M}+\mathrm{H}]^{+}$282.0322, found 282.0304.

1-氟异色酮并 [4,3-c]-6-喹啉 (5g): 白色固体, 产率 54\%. m.p. $>250{ }^{\circ} \mathrm{C} ;{ }^{1} \mathrm{H}$ NMR $\left(400 \mathrm{MHz}, \mathrm{CDCl}_{3}\right) \delta: 9.63$ (s, 1H), 8.50 (d, $J=7.8 \mathrm{~Hz}, 1 \mathrm{H}), 8.37$ (d, $J=8.0 \mathrm{~Hz}, 1 \mathrm{H})$, $8.31(\mathrm{~d}, J=8.4 \mathrm{~Hz}, 1 \mathrm{H}), 7.99 \sim 7.95(\mathrm{~m}, 1 \mathrm{H}), 7.74 \sim 7.69$ $(\mathrm{m}, 1 \mathrm{H}), 7.67 \sim 7.61(\mathrm{~m}, 1 \mathrm{H}), 7.56 \sim 7.50(\mathrm{~m}, 1 \mathrm{H}) ;{ }^{13} \mathrm{C}$ NMR $\left(100 \mathrm{MHz}, \mathrm{CDCl}_{3}\right) \delta: 159.8,158.1(\mathrm{~d}, J=248.8 \mathrm{~Hz}$, C-F), 153.0, 145.9, 135.9, 133.3, 131.3, 130.1, 127.9, $127.8,121.8,121.4,118.0,117.9,115.6,115.5,110.2$; HRMS (ESI) calcd for $\mathrm{C}_{16} \mathrm{H}_{9} \mathrm{FNO}_{2}[\mathrm{M}+\mathrm{H}]^{+}$266.0617, found 266.0602 .

1-氯异色酮并 [4,3-c]喹啉 (5h): 白色固体, 产率 $61 \%$. m.p. $>250{ }^{\circ} \mathrm{C} ;{ }^{1} \mathrm{H}$ NMR (400 MHz, $\left.\mathrm{CDCl}_{3}\right) \delta: 9.70$ (s, $1 \mathrm{H}), 8.51(\mathrm{dd}, J=8.0,1.2 \mathrm{~Hz}, 1 \mathrm{H}), 8.48 \sim 8.45(\mathrm{~m}, 1 \mathrm{H})$, $8.35(\mathrm{~d}, J=8.0 \mathrm{~Hz}, 1 \mathrm{H}), 8.00 \sim 7.93(\mathrm{~m}, 2 \mathrm{H}), 7.74 \sim 7.69$ $(\mathrm{m}, 1 \mathrm{H}), 7.65 \sim 7.60(\mathrm{~m}, 1 \mathrm{H}) ;{ }^{13} \mathrm{C}$ NMR $(100 \mathrm{MHz}$, $\left.\mathrm{CDCl}_{3}\right) \delta: 159.7,153.2,146.0,145.0,135.8,133.7,133.0$, $131.2,131.1,129.9,127.6,121.6,121.2,121.1,120.1$, 109.8; HRMS (ESI) calcd for $\mathrm{C}_{16} \mathrm{H}_{9} \mathrm{ClNO}_{2}[\mathrm{M}+\mathrm{H}]^{+}$ 282.0322, found 282.0306 .

异色酮并 [4,3-c]喹啉 (5i): 白色固体, 产率 54\%. m.p. $>250{ }^{\circ} \mathrm{C} ;{ }^{1} \mathrm{H}$ NMR $\left(400 \mathrm{MHz}, \mathrm{CDCl}_{3}\right) \delta$ : 9.58 (s, $1 \mathrm{H}), 8.52(\mathrm{~d}, J=8.2 \mathrm{~Hz}, 1 \mathrm{H}), 8.49$ (d, $J=8.0 \mathrm{~Hz}, 1 \mathrm{H}), 8.34$ $(\mathrm{d}, J=8.0 \mathrm{~Hz}, 1 \mathrm{H}), 8.16(\mathrm{~d}, J=8.4 \mathrm{~Hz}, 1 \mathrm{H}), 7.97 \sim 7.92$ (m, $1 \mathrm{H}), 7.85 \sim 7.81(\mathrm{~m}, 1 \mathrm{H}), 7.72 \sim 7.66(\mathrm{~m}, 2 \mathrm{H}) ;{ }^{13} \mathrm{C}$ NMR $\left(100 \mathrm{MHz}, \mathrm{CDCl}_{3}\right) \delta: 160.0,153.2,148.8,145.4$, $135.6,133.5,131.1,131.0,129.5,129.3,127.7,122.0$, 121.4, 121.1, 118.6, 109.1; HRMS (ESI) calcd for $\mathrm{C}_{16} \mathrm{H}_{10} \mathrm{NO}_{2}[\mathrm{M}+\mathrm{H}]^{+}$248.0711, found 248.0696.
3.2.4 2-(6-溴-4-羟基喹啉-3-基)苯甲酰胺 (6) 的合成

将化合物 5a (0.06 g, $0.18 \mathrm{mmol}$ )和胺类化合物(2.04 $\mathrm{mmol}$ )溶于二甲苯 $(15 \mathrm{~mL}), \mathrm{N}_{2}$ 保护下加热回流反应 $12 \mathrm{~h}$ (TLC 监测反应进程). 减压蒸除溶剂, 硅胶柱层析提纯 [洗脱剂: $V$ (乙酸乙酯) : $V$ (甲醇 $)=1: 3$ ] 得到化合物 6 .

2-(6-溴-4-羟基喹啉-3-基)- $N$-(2-(二甲氨基)乙基)苯 甲酰胺(6a): 白色固体, 产率 56\%. m.p. $150 \sim 151{ }^{\circ} \mathrm{C} ;{ }^{1} \mathrm{H}$ NMR (400 MHz, CD 3 OD) $\delta: 8.41(\mathrm{~d}, J=2.3 \mathrm{~Hz}, 1 \mathrm{H}), 7.99$ (s, 1H), 7.80 (dd, $J=8.9,2.3 \mathrm{~Hz}, 1 \mathrm{H}), 7.59$ (dd, $J=7.6,1.2$ $\mathrm{Hz}, 1 \mathrm{H}), 7.56 \sim 7.50(\mathrm{~m}, 2 \mathrm{H}), 7.46 \sim 7.41(\mathrm{~m}, 1 \mathrm{H}), 7.40 \sim$ $7.37(\mathrm{~m}, 1 \mathrm{H}), 3.35 \sim 3.32(\mathrm{~m}, 2 \mathrm{H}), 2.37$ (t, $J=6.9 \mathrm{~Hz}, 2 \mathrm{H})$, $2.17(\mathrm{~s}, 6 \mathrm{H}) ;{ }^{13} \mathrm{C}$ NMR $\left(100 \mathrm{MHz}, \mathrm{CD}_{3} \mathrm{OD}\right) \delta: 176.5$, $172.4,141.0,140.0,138.3,136.0,134.7,132.3,131.2$, 129.0, 128.7, 128.4, 127.9, 123.1, 121.7, 118.3, 58.7, 45.1, 37.9; HRMS (ESI) calcd for $\mathrm{C}_{20} \mathrm{H}_{21} \mathrm{BrN}_{3} \mathrm{O}_{2}[\mathrm{M}+\mathrm{H}]^{+}$ 414.0817, found 414.0809.

2-(6-澳-4-羊基喹啉-3-基)- $N$-(3-(二甲氨基)丙基)苯 甲酰胺(6b): 白色固体, 产率 $56 \%$. m.p. $134 \sim 135{ }^{\circ} \mathrm{C}$; ${ }^{1} \mathrm{H}$ NMR $\left(400 \mathrm{MHz}\right.$, DMSO- $\left.d_{6}\right) \delta: 8.23(\mathrm{~d}, J=2.4 \mathrm{~Hz}$, $1 \mathrm{H}), 8.00 \sim 7.98(\mathrm{~m}, 1 \mathrm{H}), 7.97(\mathrm{~s}, 1 \mathrm{H}), 7.80(\mathrm{dd}, J=8.0$, $2.4 \mathrm{~Hz}, 1 \mathrm{H}), 7.55(\mathrm{~d}, J=8.8 \mathrm{~Hz}, 1 \mathrm{H}), 7.48 \sim 7.42(\mathrm{~m}, 2 \mathrm{H})$, $7.40 \sim 7.34(\mathrm{~m}, 2 \mathrm{H}), 3.04(\mathrm{dd}, J=12.8,6.8 \mathrm{~Hz}, 2 \mathrm{H}), 2.04 \sim$ $1.99(\mathrm{~m}, 2 \mathrm{H}), 1.96(\mathrm{~s}, 6 \mathrm{H}), 1.41 \sim 1.33(\mathrm{~m}, 2 \mathrm{H}) ;{ }^{13} \mathrm{C} \mathrm{NMR}$ $\left(100 \mathrm{MHz}, \mathrm{DMSO}-d_{6}\right) \delta: 173.6,168.7,138.7,138.6,138.3$, 134.3, 133.7, 131.2, 129.0, 127.7, 127.4, 127.0, 126.8, $121.4,121.0,115.8,56.6,44.9,37.3,26.9$; HRMS (ESI) calcd for $\mathrm{C}_{21} \mathrm{H}_{23} \mathrm{BrN}_{3} \mathrm{O}_{2}[\mathrm{M}+\mathrm{H}]^{+}$428.0973, found 428.0973 .

2-(6-溴-4-差基喹啉-3-基)- $N$-(3-吗啉丙基)苯甲酰胺 (6c): 白色固体, 产率 61\%. m.p. $189 \sim 191{ }^{\circ} \mathrm{C} ;{ }^{1} \mathrm{H}$ NMR $\left(500 \mathrm{MHz}, \mathrm{DMSO}-d_{6}\right) \delta: 8.22(\mathrm{~d}, J=2.4 \mathrm{~Hz}, 1 \mathrm{H}), 7.97 \sim$ $7.94(\mathrm{~m}, 2 \mathrm{H}), 7.81(\mathrm{dd}, J=8.0,2.4 \mathrm{~Hz}, 1 \mathrm{H}), 7.55$ (d, $J=$ $8.8 \mathrm{~Hz}, 1 \mathrm{H}), 7.47 \sim 7.43(\mathrm{~m}, 2 \mathrm{H}), 7.40 \sim 7.34(\mathrm{~m}, 2 \mathrm{H}), 3.47$ $(\mathrm{t}, J=4.5,4 \mathrm{H}), 3.05(\mathrm{dd}, J=6.7,6.0,2 \mathrm{H}), 2.11(\mathrm{~s}, 4 \mathrm{H})$, $2.08 \sim 2.04(\mathrm{~m}, 2 \mathrm{H}), 1.41 \sim 1.34(\mathrm{~m}, 2 \mathrm{H}) ;{ }^{13} \mathrm{C} \mathrm{NMR}(125$ MHz, DMSO- $\left.d_{6}\right) \delta$ : 174.1, 169.1, 139.0, 138.9, 138.7, 134.7, 134.0, 131.6, 129.4, 128.1, 127.8, 127.4, 127.1, 121.8, 121.3, 116.2, 66.6, 56.2, 53.6, 37.6, 26.3; HRMS (ESI) calcd for $\mathrm{C}_{23} \mathrm{H}_{25} \mathrm{BrN}_{3} \mathrm{O}_{3}[\mathrm{M}+\mathrm{H}]^{+} 470.1079$, found 470.1075 .

2-(6-溴-4-差基喹啉-3-基)- $N$-(2-哌啶乙基)苯甲酰胺 (6d): 白色固体, 产率 66\%. m.p. $156 \sim 158{ }^{\circ} \mathrm{C} ;{ }^{1} \mathrm{H}$ NMR $\left(500 \mathrm{MHz}\right.$, DMSO- $\left.d_{6}\right) \delta: 8.22(\mathrm{~d}, J=2.4 \mathrm{~Hz}, 1 \mathrm{H}), 7.99(\mathrm{~s}$, $1 \mathrm{H}), 7.81(\mathrm{dd}, J=8.8,2.4 \mathrm{~Hz}, 1 \mathrm{H}), 7.72 \sim 7.68(\mathrm{~m}, 1 \mathrm{H})$, $7.56(\mathrm{~d}, J=8.8 \mathrm{~Hz}, 1 \mathrm{H}), 7.48 \sim 7.44(\mathrm{~m}, 2 \mathrm{H}), 7.40 \sim 7.34$ 
$(\mathrm{m}, 2 \mathrm{H}), 3.11(\mathrm{dd}, J=12.9,6.5 \mathrm{~Hz}, 2 \mathrm{H}), 2.11 \sim 2.08(\mathrm{~m}$, $6 \mathrm{H}), 1.37 \sim 1.31(\mathrm{~m}, 4 \mathrm{H}), 1.29 \sim 1.27(\mathrm{~m}, 2 \mathrm{H}) ;{ }^{13} \mathrm{C} \mathrm{NMR}$ $\left(125 \mathrm{MHz}, \mathrm{DMSO}-d_{6}\right) \delta: 174.0,169.0,139.1,139.1,139.0$, $138.4,134.7,131.6,129.6,128.1,127.9,127.4,127.2$, 121.6, 121.3, 116.2, 57.8, 54.3, 37.0, 25.9, 24.4; HRMS (ESI) calcd for $\mathrm{C}_{23} \mathrm{H}_{25} \mathrm{BrN}_{3} \mathrm{O}_{2}[\mathrm{M}+\mathrm{H}]^{+} 454.1130$, found 454.1125 .

\subsection{5 细胞毒活性测试实验}

采用 MTT 法, 以喜树碱(CPT)为阳性对照药, 测试 了化合物 $\mathbf{4 a} \sim \mathbf{6 d}$ 对五种人源肿瘤细胞株(胃癌细胞 MGC-803、肺癌细胞 NCI-H460、卵巢癌细胞 KOV3、 膀胱癌细胞 $\mathrm{T}-24$ 、肝癌细胞 $\mathrm{HepG}$ ) 和人正常肝细胞 HL-7702 的体外细胞毒活性, 具体实验过程参照文献方 法[26].

辅助材料(Supporting Information) 化合物 $4 \sim 6$ 的 ${ }^{1} \mathrm{H}$ $\mathrm{NMR},{ }^{13} \mathrm{C} \mathrm{NMR}$ 及 HRMS 原始谱图. 这些材料可以免 费从本刊网站(http://sioc-journal.cn/)上下载.

\section{References}

[1] Cheng, B.; Zeng, J. G. Chin. J. Org. Chem. 2012, 32, 1605 (in Chinese).

(程辟, 曾建国, 有机化学, 2012, 32, 1605.)

[2] Dvorak, Z.; Kuban, V.; Klejdus, B.; Hlavac, J.; Vicar, J.; Ulrichova, J.; Simanek, V. Heterocycles 2006, 68, 2403.

[3] Harayama, T. Rec. Res. Develop. Org. Chem. 2005, 9, 15.

[4] Styskala, J.; Hlavac, J.; Cankar, P. Tetrahedron 2013, 69, 4670.

[5] Jiang, J.; Ma, H.; Hu, S.; Cheng, L.; Wang, F.; Zhang, G. Nat. Prod. Res. 2018, 1.

[6] Agbo, J. B. P. A. A.; Mpetga, J. D. S.; Bikanga, R.; Tchuenguem, R. T.; Tsafack, R. B. N.; Awouafack, M. D.; Dzoyem, J. P.; Ito, T.; Morita, H.; Tane, P. Nat. Prod. Commun. 2017, 12, 367.
[7] Wangensteen, H.; Ho, G. T. T.; Tadesse, M.; Miles, C. O.; Moussavi, N.; Mikolo, B.; Malterud, K. E. Fitoterapia 2016, 109, 196.

[8] Kumar, G. S. J. Biosci. 2012, 37, 539.

[9] Maiti, M.; Kumar, G. S. Biophys. Rev. 2009, 1, 119.

[10] Choi, W. Y.; Jin, C.-Y.; Han, M. H.; Kim, G.-Y.; Kim, N. D.; Lee, W. H.; Kim, S.-K.; Choi, Y. H. Anticancer Res. 2009, 29, 4457.

[11] Tillequin, F. Phytochem. Rev. 2007, 6, 65.

[12] Khan, H.; Ben Hadda, T.; Touzani, R. Curr. Drug Metab. 2018, 19, 986.

[13] Galadari, S.; Rahman, A.; Pallichankandy, S.; Thayyullathil, F. Phytomedicine 2017, 34, 143.

[14] Achkar, I. W.; Mraiche, F.; Mohammad, R. M.; Uddin, S. Future Med. Chem. 2017, 9, 933.

[15] Zhang, R.; Wang, G.; Zhang, P.-F.; Zhang, J.; Huang, Y.-X.; Lu, Y.-M.; Da, W.; Sun, Q.; Zhu, J.-S. J. Cell. Mol. Med. 2017, 21, 1117.

[16] Li, T. K.; Houghton, P. J.; Desai, S. D.; Daroui, P.; Liu, A. A.; Hars, E. S.; Ruchelman, A. L.; Lavoie, E. J.; Liu, L. F. Cancer Res. 2003, 63,8400 .

[17] Zhu, S.; Ruehelman, A. L.; Zhou, N.; Liu, A.; Leroy, F. Liu, L. F.; LaVoie, E. J. Bioorg. Med. Chem. 2006, 14, 3131.

[18] Feng, W.; Satyanarayana, M.; Tsai, Y. C.; Liu, A.; Leroy, F. Liu, L. F.; LaVoie, E. J. Bioorg. Med. Chem. 2009, 17, 2877.

[19] Kiselev, E.; Dexheimer, T. S.; Pommier, Y.; Cushman, M. J. Med. Chem. 2010, 53, 8716.

[20] Ruchelman, A. L.; Houghton, P. J.; Zhou, N.; Liu, A.; Liu, L. F.; Lavoie, E. J. J. Med. Chem. 2005, 48, 792.

[21] Feng, W.; Satyanarayana, M.; Tsai, Y. C.; Liu, A. A.; Liu, L. F.; Lavoie, E. J. Bioorg. Med. Chem. Lett. 2008, 18. 3570.

[22] Feng, W.; Satyanarayana, M.; Tsai, Y. C.; Liu, A. A.; Liu, L. F.; Lavoie, E. J. Bioorg. Med. Chem. 2008, 16, 9295.

[23] Feng, W.; Satyanarayana, M.; Tsai, Y. C.; Liu, A. A.; Liu, L. F.; Lavoie, E. J. Eur. J. Med. Chem. 2009, 44, 3433.

[24] Sharma, L.; Tsai, Y. C.; Liu, A. A.; Liu, L. F.; Lavoie, E. J. Eur. J. Med. Chem. 2009, 44(4), 1471.

[25] Elsayed, M. S. A.; Griggs, B.; Cushman, M. Org. Lett. 2018, 20, 5228.

[26] Zhu, P. F.; Zhao, J. F.; Yang, X. D.; Zhang, H. B. Chin. J. Org. Chem. 2014, 34, 1167 (in Chinese).

(朱培芳, 赵静峰, 羊晓东, 张洪彬, 有机化学, 2014, 34, 1167.) 